\title{
GESTÃO DEMOCRÁTICA NA ESCOLA PÚBLICA: DESAFIOS E POSSIBILIDADES PARA A CONSTRUÇÃO DA ESCOLA INCLUSIVA A PARTIR DA PANDEMIA DA COVID-ı9
}

\author{
Rosiane Sousa Pereira 1 \\ Nilcéia Frausino da Silva Pinto ${ }^{2}$
}

RESUMO: O presente artigo intitulado: Gestão Democrática na Escola Pública: Desafios e Possibilidades para a construção da Escola Inclusiva a partir da pandemia da covid-ı9, discorrem sobre as práticas desenvolvidas pela gestão escolar na perspectiva da Educação Inclusiva em uma escola da rede pública municipal. A problemática dessa pesquisa é: Como são desenvolvidas as práticas administrativas e pedagógicas da gestão democrática face à inclusão escolar de alunos com deficiência no ensino comum a partir da pandemia. Nesse viés, o objetivo da pesquisa é relatar as ações desenvolvidas pela gestão e coordenação escolar na efetivação da inclusão e participação dos alunos no processo de ensino e de aprendizagem na escola comum a partir da pandemia. Para dialogar com a temática proposta realizou-se a abordagem teórica das políticas de inclusão escolar para alunos com deficiência, o papel do gestor e coordenação escolar e os caminhos a serem percorridos para a atuação da gestão escolar democrática e inclusiva. A metodologia desenvolvida foi a pesquisa bibliográfica-leitura de livros, e-books, lives, análise de documentos como o Projeto Político Pedagógico - PPP e o Projeto Gestor. Conclui-se que apesar de existirem vários documentos, entre decretos e leis federais que garantem uma educação com qualidade e equidade para os alunos com deficiência inseridos nas escolas comuns, a gestão e coordenação escolar ainda tem dificuldades em efetivar esse direito. Ainda que esse direito esteja destacado nas propostas do Projeto Político Pedagógico e do Projeto Gestor (Democrático) sua aplicabilidade está distante da realidade, ora por falta de comprometimento dos envolvidos (professores e gestão escolar) ora por não haver uma construção coletiva do PPP que busque alternativas pedagógicas sanar as barreiras ocasionadas pela deficiência.

Palavras-chave: Gestão democrática. Inclusão escolar . Pandemia da Covid-I9.

\footnotetext{
${ }^{1}$ Univates) E-mail: rosiane.pereira@universo.univates.br

2 (Univates). Graduada em LETRAS. Especialização em Educação Especial/ Educação Inclusiva. Especialização em Interpretação da Língua Brasileira de Sinais. Especialização em Neuropsicopedagogia Educação Especial/Educação Inclusiva. Especialização em Psicopedagogia clínica e institucional. Mestranda em Ensino pela Univates. E-mail: nilceia.pinto@universo.univates.br.
} 
ABSTRACT: This article entitled: Democratic Management in Public Schools: Challenges and Possibilities for the construction of the Inclusive School from the covid-I9 pandemic, discusses the practices developed by school management from the perspective of Inclusive Education in a municipal public school. The issue of this research is: How are the administrative and pedagogical practices of democratic management developed in the face of school inclusion of students with disabilities in regular education from the pandemic. In this bias, the objective of the research is to report the actions developed by the school management and coordination in effecting the inclusion and participation of students in the teaching and learning process in the regular school after the pandemic. To dialogue with the proposed theme, the theoretical approach of school inclusion policies for students with disabilities, the role of the school manager and coordination and the paths to be followed for the performance of democratic and inclusive school management was carried out. The developed methodology was the bibliographical research-reading of books, e-books, lives, analysis of documents such as the Pedagogical Political Project - PPP and the Manager Project. It is concluded that despite the existence of several documents, including federal decrees and laws that guarantee quality and fair education for students with disabilities in regular schools, the school management and coordination still have difficulties in realizing this right. Although this right is highlighted in the proposals of the Political Pedagogical Project and the Project Manager (Democratic), its applicability is far from reality, either because of the lack of commitment of those involved (teachers and school management) or because there is no collective construction of the PPP that seeks pedagogical alternatives to remedy the barriers caused by disability.

Keywords: Democratic management. School inclusion. Covid-I9 pandemic.

\section{INTRODUÇÃO}

A presente pesquisa denominada gestão democrática na escola pública: desafios e possibilidades para a construção da escola inclusiva a partir da pandemia da covid19, surgiu da problemática observada na prática da gestão desenvolvida por algumas escolas a partir da pandemia da covid-ig.

Partindo dessa premissa, buscou-se investigar as ações desenvolvidas pela gestão e coordenação escolar de uma escola pública na efetivação das políticas públicas de educação inclusiva aos alunos com deficiência matriculados na escola, versando sobre as ações adotadas para eliminar as barreiras para o acesso ao ensino e aprendizagem desse público, na sala de aula comum. Nesse viés, o objetivo da pesquisa é relatar as ações desenvolvidas pela gestão e coordenação escolar na efetivação da inclusão e 
participação dos alunos no processo de ensino e de aprendizagem na escola comum a partir da pandemia. Para dialogar com a temática proposta realizou-se a abordagem teórica das políticas de inclusão escolar para alunos com deficiência, o papel do gestor e coordenação escolar e os caminhos a serem percorridos para a atuação da gestão escolar democrática e inclusiva. A metodologia desenvolvida foi a pesquisa bibliográfica-leitura de livros, e-books, lives, análise de documentos como o Projeto Político Pedagógico - PPP e o Projeto Gestor.

A educação é fortalecida pelas leis brasileiras como um direito constitucional de todos os indivíduos para o acesso ao ensino de qualidade, sem qualquer distinção. A primeira etapa para a garantia desse direito está na efetivação de matrícula do aluno, vale ressaltar que apenas matricular não é garantia desse acesso. A Lei Brasileira de Inclusão no $13.146 /$ is estabelece que a pessoa com deficiência tenha direito a matrícula sendo obrigatório que as escolas e instituições de ensino, públicas e particulares, não podem recusar sua matrícula. No caso especificamente direcionado aos alunos com deficiência, ela não ocorre somente nessas circunstâncias, é imprescindível que além da matrícula ocorra o acesso ao ensino com equidade. Desse modo, surge a seguinte inquietação: como as escolas públicas desenvolveram suas práticas de ensino a partir da pandemia da Covid-ı??

A gestão e coordenação escolar desempenham um papel primordial nesse processo que vai além de atividades meramente administrativas como o caso da efetivação da matrícula. Quando se trata de gestão escolar democrática, essa função ganha ainda maior proporção em suas atribuições, pois o gestor democrático desempenha suas atividades de forma articulada com toda a comunidade escolar, construindo seus objetivos de desenvolvimento de forma coletiva e participativa, buscando a transformação e inovação da escola principalmente em suas práticas metodológicas. Será que essas problematizações foram pensadas pelas escolas nesse período pandêmico?

A inclusão escolar para alunos com deficiência vem ganhando atenção especial nas leis brasileiras, dentre elas destaca-se a Lei no $13.146 /$ I5 a Lei Brasileira de Inclusão 
- LBI que entrou em vigor no ano de 2016, trazendo em seu aporte adaptações sobre a Convenção de Direitos da Pessoa com Deficiência adotada pela Organização das Nações Unidas - ONU, ocorrida no mesmo ano de vigor da LBI.

A Lei Brasileira de Inclusão representa um grande avanço na garantia dos direitos das pessoas com deficiência, assegurando acessibilidade e inclusão nos diversos aspectos da sociedade. No capítulo IV da LBI em que trata sobre a Educação, destaca-se o art. 27 ao enfatizar que:

\begin{abstract}
A educação constitui direito da pessoa com deficiência, assegurados sistema educacional inclusivo em todos os níveis e aprendizado ao longo de toda a vida, de forma a alcançar o máximo desenvolvimento possível de seus talentos e habilidades físicas, sensoriais, intelectuais e sociais, segundo suas características, interesses e necessidades de aprendizagem. Parágrafo único. É dever do Estado, da família, da comunidade escolar e da sociedade assegurar educação de qualidade à pessoa com deficiência, colocando-a a salvo de toda forma de violência, negligência e discriminação. (BRASIL, 2016.)
\end{abstract}

Com a promulgação da lei todos os espaços escolares precisam adequar-se às necessidades específicas dos alunos e ofertar o ensino acessível e inclusivo. De que forma as escolas se adequaram para atender os estudantes público-alvo da Educação Especial a partir da pandemia? Que aulas foram produzidas? Mudar a visão sobre a deficiência é imprescindível para que ela deixe de ser vista como uma condição da pessoa e passe a ser entendida como uma necessidade adaptativa para dar condições de acesso e permanência a quem precisa de equidade. Para que ocorra de fato essa transformação na concepção e atuação das escolas, as práticas e recursos pedagógicos, além da acessibilidade arquitetônica precisam estar adequados para atender as necessidades específicas dos alunos e executar no dia a dia o cumprimento da lei e dos direitos garantidos para o processo de inclusão escolar. Afinal, não é o aluno que tem que se adequar à escola, é a escola que deve obrigatoriamente adequar-se às necessidades dos educandos com deficiência. Pensar essa contextualização em tempos de pandemia é desafiador para a escola, visto que:

\footnotetext{
Uma pandemia diz respeito ao modo rápido e eficaz como um vírus se propaga entre os corpos. Mas uma pandemia também pode dizer respeito à proliferação de uma ideia, um pensamento, um comportamento, uma crença; o quanto somos contaminados ou nos deixamos contaminar por elas.
} 
Nesse sentido, parece que outras pandemias habitam esse tempo (MUNHOZ, 2020, p.II).

De acordo com Munhoz (2020), refletir a proliferação da gestão democrática nos conduz a pensar em “outras pandemias”, pois garantir a participação dos estudantes no contexto de isolamento onde o ensino passou a ser de forma on-line e offline não é uma tarefa fácil, para a escola e nem para a família, visto que o lar que é caracterizado como um lugar de aconchego passou a ser literalmente a sala de aula. E o acesso à internet? É fato que nem todos os estudantes tiveram o privilégio de assistir às aulas por meio do compartilhamento de telas, visto que nem todos possuíam acesso à internet. De que inclusão estamos falando? Qual é o papel da gestão democrática nesse contexto? As famílias foram ouvidas? Os estudantes tiveram direito à voz? Ou a organização pedagógica simplesmente ditou as regras sem a participação da comunidade escolar?

Não é o suficiente, a gestão e coordenação escolar conhecer as leis que garantem a inclusão de alunos com deficiência no ensino comum, se não houver sua aplicabilidade na prática. Incluir sem condições de acesso e permanência com qualidade e respeito às diferenças é apenas matricular. Será que o público-alvo da Educação Especial ficou apenas matriculado no período pandêmico?

A Lei de Diretrizes e Bases da Educação Nacional - LDBen, Lei no 9.394/96, no artigo 58, enfatiza que Educação Especial "é a modalidade de educação escolar, oferecida preferencialmente na rede regular de ensino, para educandos 'portadores' de necessidades especiais”. No art. 59, inciso I, preconiza que os sistemas de ensino devem garantir à todos os educandos inseridos na escola comum, “currículos, métodos, técnicas, recursos educativos e organização específicos, para atender às suas necessidades".

A Política Nacional de Educação Especial na Perspectiva Inclusiva de 2008 referência seu principal objetivo com o intuito de:

assegurar a inclusão escolar de alunos com deficiência, transtornos globais do desenvolvimento e altas habilidades/superdotação, orientando os sistemas de ensino para garantir: acesso ao ensino regular, com participação, aprendizagem e continuidade nos níveis mais elevados do ensino; transversalidade da modalidade de educação especial desde a educação 
infantil até a educação superior; oferta do atendimento educacional especializado; formação de professores para o atendimento educacional especializado e demais profissionais da educação para a inclusão; participação da família e da comunidade; acessibilidade arquitetônica, nos transportes, nos mobiliários, nas comunicações e informação; e articulação intersetorial na implementação das políticas públicas.(Brasil, 2008, p.I4)

Para efetivar a educação inclusiva ofertada nas escolas comuns a educação especial passa a integrar a proposta pedagógica da escola com a oferta de Atendimento Educacional Especializado - AEE. Desse modo cabe mencionar que o trabalho é realizado por profissionais habilitados em práticas de educação inclusiva para dar o apoio necessário à escolaridade dos alunos público-alvo da Educação Especial. Assim os professores do AEE desempenham suas funções na identificação, elaboração e organização de recursos pedagógicos e de acessibilidade que "eliminem as barreiras para a plena participação dos alunos, considerando as suas necessidades específicas. As atividades desenvolvidas no atendimento educacional especializado diferenciam-se daquelas realizadas na sala de aula comum, não sendo substitutivas à escolarização. Esse atendimento complementa e/ou suplementa a formação dos alunos com vistas à autonomia e independência na escola e fora dela." (Brasil, 2008, p.i6). De que maneira os professores do AEE desenvolveram suas práticas de ensino a partir da pandemia? Em qual momento a escola parou para discutir a vida escolar dos estudantes público-alvo da Educação Especial? Munhoz (2020, p.II) menciona que:

\footnotetext{
Nessa perspectiva, se a metade do século XX parecia apontar para um mundo que, em alguma medida, caminhava para uma derrocada de fronteiras, preconceitos, princípios moralizantes, vivemos hoje uma espécie de falência das experiências coletivas, das relações de alteridade, arrastando para trás lutas conquistadas à duras penas. Ressurge uma pandemia de ideias que diz respeito ao colapso de uma democracia, em meio ao qual discursos excludentes, autoritários e banalizadores da violência são reverberados diariamente. Tais discursos colocam em voga hierarquias tradicionais de raça, gênero, padrões de normalidade, culturas, reforçando a ideia de que há vidas com menos valor.
}

É nítido que a pandemia descortinou muitas ações que até então eram consideradas como práticas naturalizadas, dessa maneira percebe-se que a inclusão sempre foi alvo de muitas resistências, talvez um dos fatores que contribuiu com essa percepção advém das práticas discursivas produzidas pela historicidade. Nesse viés, é primordial desnaturalizar o olhar para com esse público, visto que as leis e decretos 
federais corroboram entre si na busca da efetivação dos direitos e a quebra de paradigmas educacionais excludentes. Mas somente através das mudanças nas práticas gestoras desenvolvidas, desde os sistemas de gestão educacional à gestão escolar inclusive e principalmente, a gestão escolar democrática, é que se poderá percorrer o caminho de construção a Escola Inclusiva que caminha ao encontro das necessidades singulares apresentadas pelos estudantes.

\section{PANDEMIA DA COVID-rg: O PAPEL DA EQUIPE GESTORA NA INCLUSÃO DOS ESTUDANTES PÚBLICO-ALVO DA EDUCAÇÃO ESPECIAL}

A atribuição do gestor escolar surgiu de conceitos e experiências de administradores de empresas, mas ao longo do tempo vem se reestruturando e ganhando novos significados, já que a gestão escolar apresenta características diferenciadas. Ferreira; Pereira; Nascimento (2014, p.205) afirmam que "administrar uma escola implica em traçar objetivos e metas para que juntos seus atores obtenham sucesso". De que forma a equipe gestora norteou/norteia o trabalho pedagógico dos professores a partir da pandemia?
Contudo, ao lado deste assombroso cenário, uma pandemia de resistências aparece, desdobrando-se em linhas de forças, mostrando que não estamos sozinhos. E parece tão auspicioso que possamos produzir experiências que nos permitam escutar, compartilhar, experimentar, reinventar-nos (MUNHOZ, 2020, p.II).

De acordo com Munhoz é imprescindível que o trabalho desenvolvido pela gestão democrática tenha como objetivo principal a educação escolar e a formação dos indivíduos para o pleno exercício da cidadania, seguindo os princípios e finalidades da educação previsto na Constituição Federal de 1988 e na LDBen 9394/96.

Muitas experiencias inclusivas foram construídas pelos professores para assegurar o atendimento dos estudantes, mesmo sem acesso aos recursos especializados, formações, e conhecimentos tecnológicos, eles literalmente se desdobraram para ofertar um ensino com qualidade ao seu público. É importante destacar que o trabalho docente foi muito questionado pela população a partir da pandemia, visto que os 
esforços, dedicação e investimento se caracterizaram como invisíveis aos olhos de alguns sujeitos.

Refletir sobre a inclusão no período da pandemia remete-nos a pensar sobre os conceitos inclusão, exclusão, in/exclusão e, para potencializar as nossas reflexões acerca desse assunto, citamos Veiga-Neto e Lopes:

Diante do quadro político que determina parte das condições de possibilidade para a emergência e a potência das práticas de inclusão em nosso país, torna-se urgente questionar os usos da palavra inclusão para se referir a um número cada vez maior e mais diverso de indivíduos a incluir ou já incluídos. Torna-se urgente, também, questionar os usos alargados da palavra exclusão, quando ela é entendida como "o outro da inclusão". Nesse caso, excluídos refere-se àqueles que, de alguma maneira, são discriminados pelo Estado e/ou pela sociedade (VEIGA-NETO e LOPES 20II, p.I2I).

Ancorado nas ideias de Veiga-Neto e Lopes, inspiram-se os seguintes questionamentos: O gerenciamento dos planejamentos e as conduções das aulas estão cumprindo os propósitos da inclusão? $\mathrm{O}$ cenário pandêmico caracteriza mais a inclusão ou a exclusão? O que a escola aprendeu com a pandemia? Assim, Ortiz; Corrêa; Lockmann (202I, p.I40) contextualizam que:

Num momento de exceção como o que estamos vivenciando atualmente, em que as desigualdades sociais se intensificam, as formas de acesso à internet, computador e redes sociais variam bruscamente, assim como se diferenciam as configurações familiares $e$ as possibilidades de acompanhamento dos alunos em casa; o professor vivencia uma espécie de solidão docente na condução do seu trabalho e aqui, especificamente, no atendimento dos alunos com deficiência. Esse isolamento docente é configurado por um processo de responsabilização que recai sobre os professores, mas também por um processo de autorresponsabilização, em que os próprios docentes assumem sozinhos a tarefa de adaptar as propostas a fim de atender estes alunos mesmo diante de todas as dificuldades que uma crise sanitária, econômica e social pode causar.

De acordo com a citação acima podemos perceber que a pandemia nos afastou do espaço físico de ensino, no entanto, a escola continuou em movimento, porém os professores cada um em suas residências tiveram que pensar o ensino de forma "isolada" ou seja, sem a presença física do coletivo, esse sentimento de solidão ocasionou em muitas angustias para todos, visto que a vida acadêmica dos estudantes estava sob a responsabilidade dos mesmos. Por outro lado, mesmo vivenciando uma pandemia temos as politicas publicas que regem a organização escolar, mas, afinal, o que regem esses documentos? 
No Art. $2^{\circ}$ da LDBen é estabelecido o direito à educação e o dever da família e do Estado em ofertar o ensino de qualidade e garantir que sejam respeitados os princípios de liberdade e os ideais de solidariedade humana à todos os estudantes, promovendo assim, "o pleno desenvolvimento do educando, seu preparo para o exercício da cidadania e sua qualificação para o trabalho". Para promover esse direito, deverão ser seguidos os princípios da educação enfatizados no Art. $3^{\circ}$ :

\footnotetext{
I - igualdade de condições para o acesso e permanência na escola; II liberdade de aprender, ensinar, pesquisar e divulgar a cultura, o pensamento, a arte e o saber; III - pluralismo de idéias e de concepções pedagógicas; IV respeito à liberdade e apreço à tolerância; V - coexistência de instituições públicas e privadas de ensino; VI - gratuidade do ensino público em estabelecimentos oficiais; VII - valorização do profissional da educação escolar; VIII - gestão democrática do ensino público, na forma desta Lei e da legislação dos sistemas de ensino; IX - garantia de padrão de qualidade; $X$ - valorização da experiência extra-escolar; XI - vinculação entre a educação escolar, o trabalho e as práticas sociais. XII - consideração com a diversidade étnico-racial. (Lei no 13.632 , de 2018)
}

Percebe-se que as ações desempenhadas pelas equipes gestoras escolares antes e a partir da pandemia estão pautadas em funções meramente administrativas que enfatizam o poder centralizador na função do diretor, onde todos os funcionários se tornam subordinados a uma administração reguladora e focados apenas em situações burocráticas, destoam completamente das reais atribuições de um gestor e coordenador escolar democrático. O gestor escolar, além de cuidar da parte administrativa, de recursos e processos, precisa ser um gestor de pessoas. Os gestores escolares estão conseguindo promover prática de escuta para com os pares? Ou sua função tem se caracterizado em desenvolver ações “ditadas” pela mantenedora? Será que suas atribuições estão estritamente ligadas às práticas pedagógicas desenvolvidas? Não basta apenas gerenciar, o gestor escolar democrático precisa liderar pedagogicamente sua equipe para que suas ações sejam de excelência e principalmente, democráticas. Lógico, que a escola também necessita se preocupar com a parte administrativa, no entanto, a escola precisa da atenção de ambos os lados: pedagógica e administrativa para que as ações pedagógicas possam fluir de forma mais eficaz.

\section{OS CAMINHOS A SEREM PERCORRIDOS PARA A ATUAÇÃO DA GESTÃO ESCOLAR DEMOCRÁTICA E INCLUSIVA}


O papel fundamental da gestão escolar democrática é criar e fortalecer os laços com a comunidade escolar, para avivar a parceria e potencializar o processo de ensino e de aprendizagem dos alunos de modo geral. Quando se trata dos estudantes públicoalvo da Educação Especial inseridos no ensino regular, esse fortalecimento exige além de vínculos, a troca de informações e experiências que possam corporificar as metodologias de ensino a serem adotadas e as necessidades de adaptação e de acessibilidade, seja de materiais, arquitetônica, sobre esse assunto as autoras Ortiz; Corrêa; Lockmann (2021, p.I40) afirmam que:

\begin{abstract}
Uma primeira forma de resistência já se encontra na potência do trabalho colaborativo entre professor regente, coordenação pedagógica, atendimento especializado e família, porém ele deve ressoar também em propostas escolares que priorizem o compartilhamento das experiências pedagógicas num espaço comum, seja ele físico ou virtual. ou pedagógica. Isso implica inverter a lógica de atendimento imediato às necessidades individuais dos alunos para propor estratégias pedagógicas distintas que favoreçam a todos. Pode-se e deve-se considerar as diferenças para o planejamento das atividades, mas essas diferenças não podem ser impulsionadoras de processos de individualização e sim promotoras de vivências plurais e coletivas onde todos possam se beneficiar.
\end{abstract}

A parir das discussões acima podemos compreender que um diretor escolar tem foco administrativo no controle de pessoal e material, porém, o gestor escolar democrático é sinônimo de mediação e seu fazer profissional se refere a todos as situações administrativas-pedagógicas e principalmente, à todos os envolvidos, promovendo a participação ativa e efetiva da escola e família para atingir os fins legais para o processo pedagógico escolar.

Além disso, o gestor tem um papel fundamental na condução dos objetivos e ações a serem desenvolvidas no Projeto Político Pedagógico da escola, que como qualquer ação democrática, deve ser construído coletivamente com a participação da família, comunidade e de todos os funcionários que integram o educandário. É preciso que a gestão escolar compreenda que "[...] o sentimento de pertença e qualidade da escola estão diretamente ligados ao valor social que é dado à escola. Tal valor só é possível de ser construído mediante a promoção de aberturas participativas”(FREITAS; SILVA, 2014, p.126) 
Quando se está inserido em um processo de controle do outro, o administrador controla os que devem ser controlados. A escola não é uma empresa para ser controlada da mesma forma, na qual visa o lucro financeiro, o capital. A escola é diferente em sua administração, pois o seu lucro deve ser focado na qualidade do ensino proporcionado. Somente a eficiência administrativa não garante a eficiência educacional. Isso é negação da cidadania.

O objetivo da escola é possibilitar condições para a construção de um ser humano capaz de desenvolver seu conhecimento, autonomia e prepará-lo para a vida. A educação não é transmissão do conhecimento, mas sim construção e apropriação da cultura e do saber. Se a escola realmente produz educação democrática, ela atua de forma ativa e participativa, onde o aluno não é mero receptor de informações, mas sim o autor do seu próprio conhecimento, sobre isso Freitas; Silva (2014, p. 128) afirmam que:

[...] a família é fundamental no desenvolvimento do estudante nos anos de educação básica e que, todo o ensino e aprendizagem precisam se desenvolver no contexto social do qual crianças e comunidade são membros constitutivos, é compreender o cerne da escola democrática. Isso porque, os mecanismos que precisam ser ativados para a plena participação e efetivação da escola democrática passam pela consolidação da educação como um direito e da escola como espaço para a concretização desse fim.

A atuação da gestão democrática não é fácil, mas é possível. Trabalhar de forma colaborativa e participativa entre todos os envolvidos é imprescindível e precisa estar articulada em sua proposta de trabalho e no PPP da escola para que a atuação dos professores seja pautada nos objetivos que garantam a acessibilidade pedagógica $e$ arquitetônica, contemplando assim o direito à diversidade.

O gestor precisa ter Liderança e coordenação pedagógica para realizar o trabalho democrático. Formas democráticas e direção coletiva são fundamentais para que todos compreendam que os alunos com necessidades educativas especiais inclusos nas escolas comuns, apresentam particularidades e são seres "ímpar", por isso "é fundamental que o professor nutra uma elevada expectativa em relação à capacidade de progredir dos alunos e que não desista nunca de buscar meios para ajudá-los a vencer os obstáculos escolares (Mantoan, 2003, p.38). 
É preciso mudar os objetivos que visam resultados quantitativos a serem alcançados em provas e avaliações a nível nacional. Para os que prezam pela qualidade do ensino, o que se deve levar em conta é a qualidade no processo de ensino e de aprendizagem "Nesse sentido, pode-se dizer que ao pensar em estratégias para os seus alunos, o professor assume para si a tarefa da inclusão, de modo a tornar-se o responsável pelas práticas inclusivas que desenvolve no ensino remoto" (ORTIZ; CORREA; LOCKMANN, 202I, p.133).

Transmitir conhecimento é uma concepção ultrapassada e tradicional sobre o ensino. A atuação do professor não pode se igualar a uma televisão que só transmite informações, ele deve atuar com práticas de estimulação para a construção do conhecimento de forma participativa. Essa proposta educacional atua de forma democrática, pois envolve a convivência e afirmação de todos os educandos como sujeitos do conhecimento, sejam eles com ou sem limitações ocasionadas por qualquer deficiência, os quais se apropriam do ensino com eficiência e qualidade. É preciso querer e gostar de educar para atuar de forma inclusiva.

A escola de gestão democrática precisa promover momentos de estudos e trocas de experiências para a atuação com qualidade e equidade. Não basta ter conhecimentos específicos de sua formação e disciplina para saber ensinar, é imprescindível que o professor se aproprie de práticas inclusivas para compreender como ensinar. Assim, a gestão democrática e participativa estimula e promove a interação entre todos os envolvidos. Conhece e pratica a legislação vigente com afinco. É preciso identificar os problemas educacionais para se buscar soluções de forma coletiva e colaborativa. Não basta ter uma administração eficiente e não pensar na educação de forma global. Para ser um excelente gestor é fundamental ser um excelente professor.

\section{CONSIDERAÇÕES FINAIS}

A análise realizada na pesquisa pautou-se em recortes da realidade encontrados a partir da questão norteadora: Como são desenvolvidas as práticas administrativas e pedagógicas da gestão democrática face à inclusão escolar de alunos com deficiência 
no ensino comum a partir da pandemia? Para discorrer dos dados coletados vale ressaltar o objetivo principal da pesquisa que é relatar as ações desenvolvidas pela gestão e coordenação escolar na efetivação da inclusão e participação dos alunos no processo de ensino e de aprendizagem na escola comum a partir da pandemia. Observa-se a inexistência de práticas inclusivas no ensino e avaliação dos alunos, por não estarem articuladas de forma eficaz no Projeto Político Pedagógico da escola, além disso é perceptível a falta de empenho tanto da equipe gestora quanto dos professores da sala de aula comum em buscar parcerias com os profissionais de apoio, como os professores do Atendimento Educacional Especializado e pais, para que as ações desenvolvidas ocorram de forma colaborativa e participativa. Nesse viés, foram observados diversos fatores que dificultam a construção efetiva da Escola Inclusiva pela gestão escolar democrática. Para eliminar as barreiras na busca de práticas inclusivas ressalta-se a emergência na mudança das ações do gestor escolar, com especial atenção à necessidade de: Articular com os profissionais especializados em Educação Especial pra desenvolver formação em serviço à equipe gestora/pedagógica e os professores da escola, sobre práticas inclusivas e adaptativas aos alunos especiais; Atuar de forma colaborativa com os professores para estimulá-los a desenvolverem suas práticas com equidade e qualidade, respeitando as limitações específicas de cada aluno e possibilitando condições de acesso ao currículo adaptado sempre que necessário; Elaborar o PPP de forma coletiva e participativa entre Escola, profissionais especializados na Educação Especial e família, principalmente dos alunos com necessidades especiais, para que sejam "ouvidos" e contribuam com propostas que atendam as reais necessidades educativas e adaptativas dos alunos com deficiência; Desconstruir por parte da própria gestão escolar/pedagógica e professores, concepções ultrapassadas de que os alunos com necessidades especiais não são capazes de se desenvolver e que a inclusão significa apenas "matricular".

Uma gestão escolar democrática e inclusiva não pode atuar nos "moldes" administrativos empresariais em que o objetivo principal está no lucro, pois a Escola não trabalha com o foco em vendas de produtos, mas sim, na preparação e construção de um "produto final" que é o desenvolvimento da cultura humana: a preparação do 
indivíduo para a vida em sociedade. É fundamental que ocorra a mobilização da gestão escolar na busca pela efetivação de práticas que atendam a todos os alunos com qualidade, equidade e respeito às diferenças para que se possa alcançar a construção da Escola Inclusiva.

Cabe ao gestor e coordenador escolar gerir de forma democrática um projeto educacional de qualidade pautado e legitimado no PPP, articulado de forma colaborativa e participativa entre todos que fazem parte da Escola. Nessa perspectiva é possível que os alunos inclusos na rede regular de ensino tenham seus direitos respeitados e sejam inseridos nas atividades curriculares de forma adequada $e$ adaptada.

\section{REFERÊNCIA BIBLIOGRÁFICA}

BRASIL, Lei no 13.146, de 06 de julho de 2015. Institui a Lei Brasileira de Inclusão da Pessoa com Deficiência (Estatuto da Pessoa com Deficiência). Disponível em: < http://www.planalto.gov.br/ccivil_03/_Ato2015-2018/2015/Lei/Li3146.htm>. Acesso em o7 de jun. 2021.

BRASIL, Lei no 9.394, de 20 de dezembro de 1996. Estabelece as diretrizes e bases da educação nacional. Disponível em: $\langle$ http://portal.mec.gov.br/seesp/arquivos/pdf/lei9394_ldbn〉. Acesso em o7 de junho de 202I.

FREITAS, Marisa Bueno de; SILVA, Diana de Cássia. O silêncio da escola e a escola do silêncio: resistências e aberturas para a escola democrática. Gestão Escolar e Formação Continuada de Professores - Breynner R. Oliveira \& Adriana M. Tonini Editar, Juiz de Fora - 2014, p.125 a 152.

MUNHOZ. A. V. Das Pandemias em curso. Inclusão escolar: um itinerário de formação docente / Morgana Domênica Hattge, Francieli Karine dos Santos, Daniel Marques Costa (Org.) - Lajeado: Editora Univates, 2020.

ORTIZ.Cilene de Oliveira. CORREAA. Camila Bottero. LOCKMANN Kamila. Os alunos com deficiência no ensino remoto emergencial. E-book-Pesquisar com a escola: currículo e inclusão em foco. Clarice Salete Traversini, Kamila Lockmann, Renata Sperrhake - organizadoras. São Paulo: Pimenta Cultural, 2021. 237p..

VEIGA-NETO, Alfredo; LOPES, Maura Corcini. Inclusão, exclusão, in/exclusão. In: VERVE, São Paulo, n. 20, p. 121-135, out. 20II. 


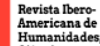

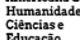

